\title{
SEROPREVALENCE OF HEPATITIS B INFECTION DURING PREGNANCY AND NEONATAL OUTCOME
}

\author{
Vishal Kamate1, Rajendra Godbole², Reshma Kamate 3
}

${ }^{1}$ Senior Resident, Department of Obstetrics and Gynaecology, Belagavi Institute of Medical Sciences, Belagavi, Karnataka. ${ }^{2}$ Associate Professor, Department of Obstetrics and Gynaecology, Belagavi Institute of Medical Sciences, Belagavi, Karnataka. 3Junior Resident, Department of Obstetrics and Gynaecology, Belagavi Institute of Medical Sciences, Belagavi, Karnataka.

ABSTRACT

\section{BACKGROUND}

The aim of this study was to determine the prevalence of HBsAg positive cases among the hospital deliveries and analyse demographic factors and foetal outcome among HBsAg positive cases with normal singleton pregnancies.

\section{MATERIALS AND METHODS}

We conducted a prospective study of 6 months during which 2561 women with otherwise normal singleton pregnancies were screened for HBsAg seropositivity in the antenatal clinic. The patients were followed up to delivery. Data were collected regarding sociodemographic factors, birth weights and foetal outcome and the results were analysed.

\section{RESULTS}

22 out of $2561(0.85 \%)$ tested positive for HBsAg. The prevalence of infection was higher in primigravidas and younger age group; $25 \%$ of the babies had low birth weight. There were no maternal and perinatal mortalities observed.

\section{CONCLUSION}

The prevalence of Hepatitis B virus infection was $0.85 \%$. The incidence was higher in the urban population, amongst primigravidas and younger age groups. There was a higher incidence of low birth weights, but the incidence of caesarean section and NICU admissions was not increased. There were no perinatal and maternal mortalities observed.

\section{KEYWORDS}

HBsAg Antigen, Perinatal Mortality and Morbidity, Low Birth Weight.

HOW TO CITE THIS ARTICLE: Kamate V, Godbole R, Kamate R. Seroprevalence of hepatitis B infection during pregnancy and neonatal outcome. J. Evolution Med. Dent. Sci. 2016;5(77):5721-5724, DOI: 10.14260/jemds/2016/1290

\section{INTRODUCTION}

Hepatitis B virus infection is prevalent all over the world and presents a significant health problem affecting 2 billion people with an estimated 240-350 million people worldwide having chronic infection. ${ }^{1,2}$ With an estimated 40-50 million people infected, India has the second highest number of chronic HBV patients in the world.3,4 The prevalence rate amongst pregnant women in India is reported to be between $0.9-11.2 \%$ by various authors. ${ }^{3,5}$ Infection with Hepatitis B virus in adults can go unnoticed in acute stage as not all cases are symptomatic. However, it can also cause life-threatening acute fulminant hepatitis in 1-2\% of acutely infected patients. The incubation period varies from 45 to 160 days and in the acute phase it usually causes a nonspecific prodrome of fever, myalgia, headache and malaise causing it to go unnoticed. As many as $50 \%$ acute infections are asymptomatic. Fatality rates of acute Hepatitis B infection have been reported to be 0.5 $1.5 \%$, mostly from acute fulminating hepatitis, which has 60 $70 \%$ mortality. Most notable complications of the infection are seen years later due to chronic infection.

Financial or Other, Competing Interest: None.

Submission 29-04-2016, Peer Review 12-09-2016,

Acceptance 19-09-2016, Published 24-09-2016.

Corresponding Author:

Dr. Vishal Kamate,

H. No. 58, $2^{\text {nd }}$ Cross

Mahadwar Road,

Belagavi-590002, Karnataka.

E-mail:vkamate@gmail.com

DOI: $10.14260 /$ jemds $/ 2016 / 1290$
Chronic HBV infection is an established cause of chronic hepatitis, cirrhosis of the liver, hepatocellular carcinoma and liver failure. More than $25 \%$ of chronic carriers develop chronic active hepatitis ending in cirrhosis and they are 12300 times more likely to develop hepatocellular carcinoma than general population. ${ }^{2}$ Pregnancy gives an opportunity to screen the woman for HBsAg seropositivity and also to prevent the rate of vertical transmission in seropositive mothers.

Hepatitis B Virus (HBV) is a DNA virus of the Hepadnaviridae family with a partially double-stranded DNA surrounded by a shell containing hepatitis B surface antigen (HBsAg). Other antigenic components include the hepatitis B core antigen ( $\mathrm{HBcAg}$ ) and hepatitis $\mathrm{B}$ e antigen ( $\mathrm{HBeAg}$ ). Of the three antigens, antibodies formed against HBsAg and HBcAg provide immunity. 6 The HBV genome harbours 3200 nucleotides and it can encode four groups of proteins and their regulatory components by shifting the reading frames over the same genetic matter. IgM anti-HBc signifies recent infection and usually disappears within six months. HBsAg persisting for a period exceeding six months is defined as chronic HBV infection. Presence of $\mathrm{HBeAg}$ antigen indicates active viral replication, high viral loads in the blood and subsequently high infectivity. The virus is present in blood, saliva, vaginal secretions and menstrual blood of affected individuals. ${ }^{7}$ The virus has been shown to remain infectious at room temperatures for as long as 7 days. $^{2}$

Screening for HBsAg antigen in blood of pregnant patients ought to be universal, but that is not the case. As per the data released by UNICEF in Feb 2016 in India in the year 2013-14, antenatal care services with at least four visits were accessed by $45 \%$ patients overall, the rates being $40 \%$ in urban areas 
and $59 \%$ in rural areas. ${ }^{8}$ Under-utilisation of modern health services, high illiteracy rates among women, early marriages and poor socio-economic states being the important reasons. ${ }^{9}$ It is not uncommon to see a patient coming in labour without any HBsAg reports. The prevalence of HBsAg positive pregnancies can give an idea of the prevalence of $\mathrm{HBsAg}$ positive patients in the community at large. However, it is not just sufficient to identify an HBsAg positive mother. Carrier patients and their families should be given complete information of the risks and complications of chronic HBsAg infection, the risk of transmission to the babies, the complications and risks to the child in case of vertical transmission, strategies that are available to prevent and reduce the risk of vertical transmission and also how and where to avail the preventive measures. It is estimated that vertical transmission is less than $10 \%$ if mother is $\mathrm{HBsAg}$ positive and $\mathrm{HBeAg}$ negative, but the transmission rates increase to $70-90 \%$ if the mother is HBeAg positive. One study has suggested that HBeAg crosses the placenta. ${ }^{10}$ Childhood chronic HBsAg infection has $25 \%$ chance of developing chronic liver disease, cirrhosis of liver or hepatocellular carcinoma. ${ }^{2}$

The recombinant HBV vaccine was developed in 1984 and now over 160 countries use it for universal infant vaccination, especially in areas where the infection is endemic. The world health organisation recommends to give the first dose to all infants within 24 hours of birth followed by 2 to 3 doses as part of routine immunisation services. In adults a 3 dose regimen is recommended at 0,1 and 6 months and is said to produce effective antibody response in $90 \%$ individuals $<40 \mathrm{yrs}$. age after the three dose regimen. ${ }^{11}$ The efficacy of the vaccine decreases with age and is also affected by other factors like smoking, obesity and immune suppression. In adults the vaccine is recommended for individuals with high risk factors individuals with multiple sexual partners, intravenous drug users, homosexual men, patients with chronic liver disease, end-stage renal disease patients on haemodialysis, HIV positive patients, individuals at risk of occupational exposures, travellers to endemic areas and household contacts of persons with chronic HBV infection. ${ }^{11}$ The Hepatitis B Immune Globulin (HBIG) is prepared from plasma of donors with high concentration of anti-HBs. It is usually given along with HBV vaccine for post exposure prophylaxis and immunisation of infants born to HBsAg positive mothers. It provides temporary protection for a period of 3-6 months when given in standard doses. Pregnancy is not a contraindication for $\mathrm{HBsAg}$ vaccination. The developing foetus is not at risk of any adverse events and the vaccine is not known to cause any teratogenic effects.

\section{MATERIALS AND METHODS}

We conducted a prospective study of six months from April 2015 to Sept 2015. Patients included in the study were selected from the Antenatal Clinic. Women included in the study had singleton pregnancy. During the initial antenatal investigation, five millilitres of blood was taken from each subject for HBsAg test. After centrifugation, the samples were analysed at the hospital laboratory for HBsAg. The test was performed using a SD Biokit. The patients who tested positive for HBsAg were counselled and followed till delivery. Data were collected regarding sociodemographic factors, birth weight, mode of delivery and foetal outcome and the results were analysed.

\section{RESULTS}

Of 2561 women screened 815 (32\%) were from urban areas and $1746(68 \%)$ were from rural areas. Of these, 22 patients $(0.85 \%)$ tested positive for $\mathrm{HbsAg}$.

\begin{tabular}{|c|c|c|}
\hline Age & No. of Cases & $\mathbf{\%}$ \\
\hline$<20$ yrs. & 2 & $0.08 \%$ \\
\hline $20-25$ yrs. & 12 & $0.47 \%$ \\
\hline $26-30$ yrs. & 7 & $0.27 \%$ \\
\hline $30-35$ yrs. & 1 & $.04 \%$ \\
\hline$>35$ yrs. & 0 & \\
\hline \multicolumn{3}{|c|}{ Table 1: Age Distribution } \\
\hline
\end{tabular}

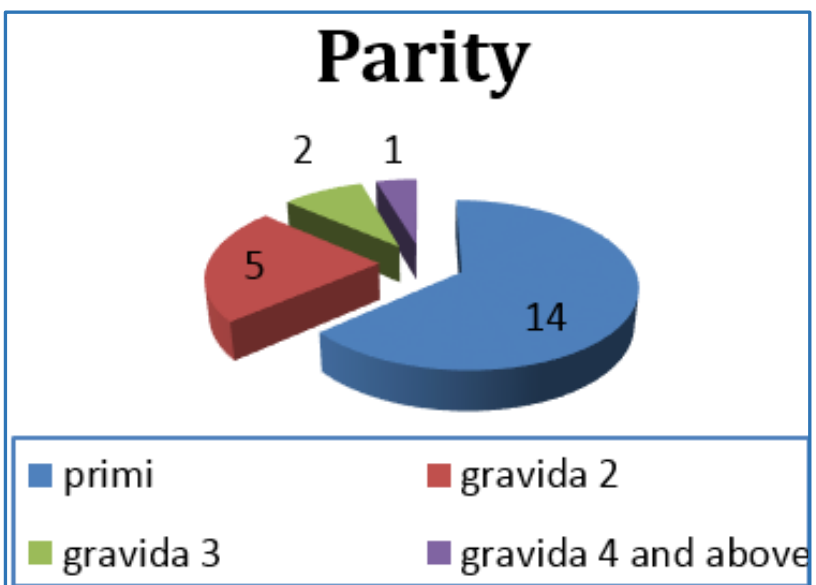

Of the 22 patients 2 patients were lost to follow-up and remaining 20 delivered in BIMS, Belagavi. Amongst these, 5 patients underwent caesarean section for obstetric indication and 15 delivered vaginally; 2 patients had altered LFTS at the time of admission with raised SGPT and SGOT. There were no maternal mortalities amongst our cases. Babies of all the patients were given HBV vaccine and hepatitis B immunoglobulin within 12 hours of birth; 3 babies amongst the vaginal deliveries required NICU admission. Incidence of low birth weights was $25 \%$ (5) in our study. However, there were no perinatal mortalities observed.

\begin{tabular}{|c|c|c|c|c|}
\hline $\begin{array}{c}\text { Mode of } \\
\text { Delivery }\end{array}$ & No. & $\begin{array}{c}\text { Low Birth } \\
\text { Weight }\end{array}$ & $\begin{array}{c}\text { NICU } \\
\text { Admissions }\end{array}$ & $\begin{array}{c}\text { Neonatal } \\
\text { Deaths }\end{array}$ \\
\hline $\begin{array}{c}\text { Vaginal } \\
\text { Delivery }\end{array}$ & 14 & 03 & 02 & 0 \\
\hline LSCS & 06 & 02 & 01 & 0 \\
\hline \multicolumn{5}{|c|}{ Table 2 } \\
\hline
\end{tabular}

One $(2.7 \%)$ HBsAg positive woman was a health care worker.

\section{DISCUSSION}

HBV infection is a major health problem causing considerable morbidity and mortality. According to the WHO, 500,000 to 700,000 patients die annually as a result of HBV related liver diseases like liver cirrhosis, end disease or hepatocellular carcinoma, 1 majority of them in the developing countries. India falls into the intermediate endemicity area as regards the prevalence of HBV infection. ${ }^{5}$ Vertical and horizontal transmission in the perinatal period and early childhood are the major ways of propagation of this infection in India.3,12,13 Infection acquired during the neonatal period carries a high risk of developing into persistent infection. ${ }^{1}$ 
It is estimated that amongst women who develop acute HBsAg infection in the first trimester, about $10 \%$ of the newborns are HBsAg positive at birth; $80 \%$ newborns will become positive if prophylactic therapy is not instituted in acute third trimester infections. 14,15,16 Intrapartum exposure to infectious blood and vaginal secretion is the most important cause for neonatal HBV infection, though sometimes the spread also occurs by transplacental viral spread. ${ }^{17}$ Hepatitis B vaccine is considered to be safe if administered during pregnancy.

No significant adverse maternal effects or foetal teratogenic effects have been reported in the literature if the vaccine is given during pregnancy. Pregnant women who are negative for HBsAg and are otherwise at high risk of contacting the infection can be offered immunisation during pregnancy. 18

The infants of potentially infectious mothers are treated with HBV Human Hyperglobulin (HBIG) at delivery and simultaneously active immunoprophylaxis is initiated. ${ }^{6}$ This approach is effective in preventing chronic HBV in approximately $85 \%$ neonates, ${ }^{19}$ if the vaccination and passive immunisation is initiated within 24 hours. Prevention provided by HBIG remains effective for 3-6 months. However, the efficacy of passive immunisation is decreased if given beyond 24 hours of birth. It is recommended to start the activepassive immunisation process within 12 hours of birth.11 The combined approach of giving immunoglobulin and active immunisation is more effective than giving either one alone. However, when HBIG is not available active immunisation alone should be given. Different studies in India have reported seroprevalence of HBsAg to be between $0.9 \%$ to $1.8 \% .3,12,20$ In our study, it was $0.85 \%$ which is comparable to other studies. These rates are less compared to African studies, where prevalence as high as $6.6 \%$ have been reported. ${ }^{21}$

\begin{tabular}{|c|c|c|}
\hline Author & $\begin{array}{c}\text { Prevalence } \\
\text { Rates }\end{array}$ & Region \\
\hline Our study & $0.85 \%$ & North Karnataka \\
\hline Manisha Dwiwedi. ${ }^{1}$ & $0.9 \%$ & Allahabad, U.P \\
\hline S. Chaterjee & $0.85 \%$ & Kolkatta, W.B \\
\hline K. S. Saraswathi & $0.9 \%$ & Hyderabad, A.P \\
\hline \multicolumn{2}{|c|}{ Table 3: Comparison with other Indian Studies } \\
\hline
\end{tabular}

Administration of HBIG in a dose of 200 IU IM every week from $28^{\text {th }}$ week of gestation reduces the intrauterine infection. We observed a slight non-significant decline in HBsAg positivity rate with increasing age. Antiviral therapy is recommended by some studies in the third trimester of pregnancy to reduce the perinatal transmission of HBV. HBV DNA levels should be measured in the second trimester of pregnancy and if HBV DNA level is > $7 \log \mathrm{IU} / \mathrm{mL}$, then prophylactic treatment should be considered in the early third trimester with lamivudine, tenofovir or telbivudine. ${ }^{22}$ If the patient develops acute liver disease during pregnancy, the treatment should be directed towards remission of liver disease and prevention of preterm birth. Breastfeeding by HBsAg-positive women does not increase rates of perinatal transmission if appropriate immunoprophylaxis is given to the newborns. ${ }^{23,24}$ However, if the patient is started on antiviral drugs during the third trimester, these should be discontinued during breast feeding in order to minimise the exposure of the foetus to these drugs. ${ }^{22}$

A recent study concluded that HbsAg carriers had increased risk of developing gestational diabetes mellitus, threatened preterm labour and antepartum haemorrhage which can be related to the chronic inflammatory state in these patients. ${ }^{25}$

\section{CONCLUSION}

The prevalence of HbsAg seropositivity amongst patients attending Antenatal Clinic at BIMS, Belagavi, was 0.85\%. The prevalence of seropositivity is higher in primigravida patients compared to multigravidas and the prevalence rate decreases with increasing age. In our study seropositivity for HBsAg did not have any effect on perinatal and maternal outcome. All patients attending antenatal O.P.D. should be screened for HBsAg and infants of HBsAg positive mothers should be administered HBIG and HBV at birth. The pregnant woman with hepatitis B infection and their infants should be closely monitored during and after pregnancy.

\section{REFERENCES}

1. World Health Organisation. Department of communicable diseases surveillance and response. Hepatitis B. WHO/CDS/CSR/LYO/2002.

2. Hep B-Pink Book-Centers for Disease Control and Prevention. Epidemiology and prevention of vaccine preventable diseases. Chapter 10. 149-174.

3. Dwivedi M, Misra SP, Misra V, et al. Seroprevalence of hepatitis $\mathrm{B}$ infection during pregnancy and risk of perinatal transmission. Indian J Gastroenterol 2011;30(2):66-71.

4. Geeta MG, Riyaz A. Prevention of mother to child transmission of hepatitis B infection. Indian Pediatr 2013;50(2):189-92.

5. Tandon BN, Acharya SK, Tandon A. Epidemiology of hepatitis B virus infection in India. Gut 1996;38(suppl 2):S56-9.

6. Guidelines for the prevention, care and treatment of persons with chronic Hepatitis B infection. World Health Organization. march 2015.

7. Trehanpati N, Hissar S, Shrivastav S, et al. Immunological mechanisms of hepatitis B virus persistence in newborns. Indian J Med Res 2013;138(5):700-10.

8. UNICEF: Global databases. Antenatal care coverage: at least four visits-percentage. Update feb 2016. Data.unicef.org.

9. Gupta RK, Shora TN, Verma AK, et al. Knowledge regarding antenatal care services, its utilization, and delivery practices in mothers (aged 15-49 years) in a rural area of North India. Tropical Journal of Medical Research 2015;18(2):89-94.

10. Wang JS, Zhu QR. Infection of the fetus with hepatitis B e antigen via the placenta. Lancet 2000;355(9208):989.

11. Recommendations of the Advisory Committee on Immunization Practices (ACIP) Part II: Immunization of Adults. A comprehensive immunization strategy to eliminate transmission of hepatitis b virus infection in the united states. Centers for Disease Control and Prevention(CDC). Morbidity and Mortality Weekly Report December 8, 2006;55(RR-16):1-25.

12. Saraswathi KS, Aljabri F. The study of prevalence of hepatitis B surface antigen during pregnancy in a tertiary care hospital, South India. Der Pharmacia Lettre 2012;4(3):983-5. 


\section{Jemds.com}

13. Chowdhury SD, Eapen CE. Perinatal transmission of hepatitis B. Hepatitis B Annual 2009;6(1):80-8.

14. Bohidar NP. Hepatitis $B$ virus infection in pregnancy. Hepatitis B Annual 2004;1(1):199-209.

15. Sweet RL. Hepatitis B infection in pregnancy. Obstet Gynecol Report 1990;2:128.

16. Reinus J, Leikin E. Viral hepatitis in pregnancy. Clin Liver Dis 1999;3:115-30.

17. Okada K, Kamiyama I, Inomata $M$, et al. $E$ antigen and anti$E$ in the serum of asymptomatic carrier mothers as indicators of positive and negative transmission of hepatitis $\mathrm{B}$ virus to their infants. $\mathrm{N}$ Engl J Med 1976;294(14):746-9.

18. Ho V, Ho W. Hepatitis B in pregnancy: specific issues and considerations. J Antivir Antiretrovir 2012;4(3):051-9.

19. Stevens CE, Taylor PE, Tong MJ, et al. Yeast-recombinant hepatitis B vaccine. Efficacy with hepatitis B immune globulin in prevention of perinatal hepatitis B virus transmission. JAMA 1987;257(19):2612-6.

\section{Original Research Article}

20. Chatterjee S, Ravishankar K. Hepatitis B prevalence during pregnancy. Indian Pediatrics 2005;46:1005-8.

21. Utoo BT. Hepatitis B surface antigenemia (HBsAg) among pregnant women in southern Nigeria. African Health Sciences 2013;13(4):1139-43.

22. Yogeswaran K, Fung SK. Chronic hepatitis B in pregnancy: unique challenges and opportunities. The Korean Journal of Hepatology 2011;17(1):1-8.

23. The Royal Australian and New Zealand College of Obstetricians and Gynaecologists. Management of hepatitis B in pregnancy. C-Obs 50.

24. Hill JB, Sheffield JS, Kim MJ, et al. Risk of hepatitis B transmission in breast-fed infants of chronic hepatitis B carriers. Obstet Gynecol 2002;99(6):1049-52.

25. Tse KY, Ho LF, Lao T. The impact of maternal HBsAg carrier status on pregnancy outcomes: a case-control study. Journal of Hepatology 2005;43(5):771-5. 